\title{
CONSENSO Y CONFLICTO EN LA EDUCACIÓN POLÍTICA EN LA ESCUELA. RELECTURAS EN TORNO DEL DISCURSO PEDAGÓGICO DEL PRIMER PERONISMO
}

\author{
Carolina Mamilovich ${ }^{1}$
}

RESUMEN: En el presente trabajo se abordará la problemática de la educación política en las instituciones escolares a partir del caso paradigmático del discurso pedagógico del primer peronismo. Para ello se intentará contraponer dos corrientes interpretativas que en base a sus construcciones teóricas instituyen distintos modelos de subjetivación política: por un lado, la perspectiva liberal-funcionalista que privilegia la conciliación y el consenso $y$, por otro, el enfoque nacionalpopulista, que otorga primacía al conflicto y al antagonismo.

PALABRAS-CLAVE: Educación, Política, Peronismo, Consenso, Conflicto.

RESUMO: Neste trabalho aborda-se a questão da educação política nas instituições escolares argentinas com o caso paradigmático do discurso pedagógico do primeiro peronismo como ponto de partida. Também, como parte dessa abordagem, tentase contrapor duas correntes interpretativas que baseadas nas suas próprias construções teóricas instituíram modelos diversos de subjetivação política: por um lado, a perspectiva liberal-funcionalista que privilegia a conciliação e o consenso; $e$, por outro, o enfoque nacional-populista que concede primazia ao conflito $e$ ao antagonismo.

PALAVRAS-CHAVE: Educação, Política, Peronismo, Consenso, Conflito.

Articular históricamente el pasado no significa conocerlo "tal y como verdaderamente ha sido". Significa adueñarse de un recuerdo tal y como relumbra en el instante de un peligro.

Walter Benjamin

\section{Introducción}

En la actualidad el problema de la ciudadanía ha cobrado una centralidad inusitada. De acuerdo con Isidoro Cheresky esto se debe, por un lado, a la expansión y vigencia del orden político democrático y, por otro, a la crisis de los lazos de representación y a las mutaciones del sistema institucional. Como síntoma de estas transformaciones encontramos la erosión de las identidades sociales y la

\footnotetext{
${ }^{1}$ Profesora de filosofía - Universidad de Buenos aires (UBA). E-mail: cmamilovich@yahoo.com.ar

MAMILOVICH, Carolina. Consenso y conflicto en la educación política en la escuela. Relecturas en torno del discurso pedagógico del primer peronismo. Revista Sul-Americana de Filosofia $e$ Educação. Número 15, nov/2010-abr/2011, p. 3-30.
} 
debilidad e inestabilidad normativa de la vida pública y política, esto conlleva un proceso de reconfiguración de la vida ciudadana, como parte esencial de la política democrática. (CHERESKY, 2006, p. 27-9)

En la escuela, una de las instituciones más importantes de socialización en la modernidad, repercuten de manera dramática las contradicciones del sistema político. En primer lugar, dos de las ideas básicas que han definido la formación del ciudadano durante el siglo XX -democracia y nación- se encuentran hoy en proceso de revisión. Uno de los problemas que afronta en la actualidad la formación del ciudadano es lo que Lechner llama "déficit de modernidad", entendiendo por modernidad el proceso de ciudadanización, de consagración de derechos. En segundo término, por el lugar particular que ocupa la escuela en nuestra sociedad precisamente en el centro de articulación problemático entre la obligación colectiva y los derechos individuales, cobra vital importancia repensar el sentido de la formación ciudadana sobre el horizonte de identidades políticas y pertenencias sociales inestables y contingentes.

Para el presente trabajo nos interesa indagar acerca de la socialización política a través del accionar pedagógico institucional, porque consideramos que el peronismo tornó más visible la naturaleza de la relación entre educación y política $y$, en particular, los dispositivos de control y vigilancia. Principalmente vamos a indagar las construcciones teóricas que instituyen modelos de subjetividad política en la escuela a través de la figura del ciudadano y el efecto de verdad que se produce a partir de cierta concepción de lo político. Para ello nos vamos a limitar, en primer lugar, a exponer y discutir algunas interpretaciones sobre el proyecto educativo peronista $y$, en segundo lugar, vamos a discutir determinados presupuestos de la perspectiva liberal consensualista respecto de la subjetivación política.

Analizaremos la polarización entre el abordaje de J. L. Bernetti y A. Puiggrós y el de M. B. Plotkin, a la luz de la revisión crítica de C. Somoza Rodríguez $^{2}$. Si bien las tres obras sobre las que vamos a trabajar no son

\footnotetext{
${ }^{2}$ De acuerdo con este autor el trabajo de Plotkin, M. B. Mañana es San Perón Propaganda, rituales políticos y educación en el régimen peronista (1946-1955) junto con los dos tomos sobre Historia de la Educación Argentina dirigida por A. Puiggrós y el de Carlos Escudé, El fracaso del proyecto
} 
equiparables dado que persiguen distintos objetivos, sin embargo, coinciden en el estudio de la relación entre educación y política bajo el primer peronismo.

Nuestro propósito consiste en revisar algunas líneas de lectura que mantienen su vigencia a los efectos de echar luz sobre los debates actuales. Por lo tanto, en el presente trabajo no se llevará a cabo un análisis exhaustivo de los tres libros seleccionados, sino, antes bien, nos proponemos discutir las construcciones conceptuales que sustentan una determinada interpretación a propósito de un fenómeno político.

\section{El sistema educativo como "agencia de adoctrinamiento"}

El análisis de Plotkin respecto del proyecto educativo del gobierno peronista pone el acento en la figura del líder carismático y en la función del sistema educativo como "agencia de adoctrinamiento" e instrumento de manipulación de conciencias. De acuerdo con las intenciones explicitadas por el autor, el libro se centra en el Estado y en el mensaje que éste quiere transmitir, sin ahondar en la recepción del mismo. Se propone analizar las formas que adopta el Estado peronista para generar consenso alrededor del propio régimen, $e$ intenta explorar los mecanismos simbólicos e institucionales puestos en marcha para lograr ese consenso. Es relevante tener presente la explicitación de sus intenciones generales porque nos brinda elementos teóricos para analizar los presupuestos no sólo metodológicos y epistemológicos sino también ideológicos a partir de los cuales lleva a cabo su investigación. Volveremos sobre este punto al retomar la crítica a propósito de la imagen que proyecta el texto de un agente activo y manipulador (el Estado) y de una masa receptora y pasiva (las clases trabajadoras).

La hipótesis de lectura de Plotkin se organiza en dos etapas: la primera, de "democratización" doctrina político-partidaria. El autor sostiene que en la primera etapa, Perón sólo profundiza y redefine el sistema escolar de sus predecesores inmediatos articulado

argentino, constituyen las corrientes interpretativas más importantes sobre educación y peronismo. Cfr. SOMOZA RODRÍGUEZ, M., Educación y Política en Argentina (1946-1955), Buenos Aires: Miño y Dávila, 2006, p. 23.

${ }^{3}$ El encomillado es del autor. 
alrededor del nacionalismo católico y traza una ruptura en la segunda etapa, en donde se lleva a cabo la indoctrinación. En virtud de esta línea interpretativa comienza con un brevísimo recorrido histórico a través del vínculo entre el sistema educativo y el régimen de gobierno, para centrarse luego en el estudio del proyecto peronista.

En este recorrido inicial sostiene que el sistema educativo organizado por los gobiernos liberales de fines del siglo XIX y comienzos del XX constituía un poderoso instrumento para el mantenimiento del consenso liberal. Y reconoce la preocupación de las autoridades gubernamentales por la educación patriótica a través de la inculcación de sentimientos nacionalistas como mecanismo contra las ideologías disolventes, entre ellas el anarquismo. Asimismo, destaca el rol de la escuela como agente generador de sentimientos nacionales hasta 1913, fecha en que muere José María Ramos Mejía, presidente del Consejo Nacional de Educación. Y subraya que este interés se renovó entre finales de la década de 1930 y principios de la de 1940.

Es llamativo que Plotkin sólo mencione como fundamento ideológico del sistema educativo liberal el laicismo y afirme que el gobierno de la década del 30 defendía las instituciones democráticas y los principios de soberanía popular. En sus propias palabras:

A lo largo de la década de 1930 inspectores del Consejo Nacional de Educación descubrieron la existencia de escuelas alemanas que de hecho funcionaban como verdaderos centros de adoctrinamiento nazi. En reacción a estos descubrimientos, el esfuerzo de las autoridades educativas se centró en enfatizar a través de las escuelas la importancia de la defensa de las instituciones democráticas y de los principios de la soberanía popular. (PLOTKIN, 2007, p.150)

Lamentablemente no hay un apoyo documental ni una fundamentación para darle sustento a tal afirmación, pero, en principio, nos advierte acerca de cuál es el concepto de democracia y de soberanía que maneja dicho autor. Por el contrario, hay otras interpretaciones de la política educativa de ese período que subrayan la presencia de rasgos de autoritarismo e imposición ideológica. Juan 
Carlos Tedesco sostiene que "a partir de 1930, el sistema educativo comenzó a perder progresivamente estos rasgos de neutralismo pasando a adoptar formas de imposición ideológica cada vez más ostensibles, dogmáticas y, por todo ello, más claramente autoritarias y coercitivas" (TEDESCO, 1986, p. 245)

Luego, al abordar el análisis de la educación bajo el gobierno revolucionario de 1943, destaca tres áreas de interés e innovación educativa: la introducción de la enseñanza católica, la promoción de la educación técnica y la creación de un cuerpo de maestros leales a los principios del nacionalismo católico. Finalmente, divide en tres ejes el abordaje de la etapa peronista en coincidencia con los períodos a cargo de los tres ministros de la cartera educativa: 1) 1946-1948, Belisario Gache Pirán; 2) 1948-1950, Oscar Ivanissevich; 3)1950-1955, Armando Méndez San Martín.

El recorrido que propone Plotkin parte de la legalización del decreto de 1943 que había introducido la enseñanza católica con el fin de contar con el apoyo semiexplícito de la Iglesia, avanza por las reformas del sistema educativo a través de la gestión centralizada desde el Ministerio de Educación para cambiar los programas de la escuela primaria y finaliza con el adoctrinamiento a través de los textos peronistas y el conflicto con la Iglesia para monopolizar el espacio simbólico. Según el autor: "Si durante los primeros años del gobierno de Perón se enfatizaba la necesidad de democratizar el sistema educativo, y durante los años del ministerio de Ivanissevich la de inculcar en los niños ciertos valores universales y trascendentes, en el período de Méndez San Martín la palabra clave parece haber sido "adoctrinamiento". (PLOTKIN, 2007, p.170)

Plotkin señala que en la primera etapa las prioridades de Perón en materia educativa eran similares a las del gobierno que lo precedió. A saber: a) legalizar la introducción de la enseñanza católica, b) obtener el control de la Universidad que constituía un polo opositor, c) centralizar el sistema educativo, d) expandir el sistema de educación técnica no sólo para calificar a la mano de obra sino también como instrumento de disciplinamiento de la clase obrera y e) integrar todos los niveles de educación bajo el control directo del Estado (unidad espiritual). 
Si bien este autor observa la continuidad de la preocupación por inculcar sentimientos patrióticos y amor a las tradiciones nacionales, traza una diferencia. En las décadas anteriores el nacionalismo era definido en términos negativos, esto es, como una barrera contra las ideologías disolventes y la presencia masiva de inmigrantes aún no nacionalizados. En cambio, de acuerdo con este autor, para el proyecto peronista tenía una connotación positiva: preparar a las masas para ser conducidas. En definitiva, estas coincidencias señaladas por el autor, conducen finalmente a su conclusión acerca de que Perón sólo profundizó algunas de las reformas educativas iniciadas por las autoridades militares surgidas de la revolución de junio, con el fin de transformar el sistema educativo en un mecanismo eficiente de socialización política. En sus palabras:

\begin{abstract}
Durante su gobierno Perón transformó progresivamente el sistema educativo oficial en un engranaje de su poderosa maquinaria de propaganda. Las escuelas se convirtieron en centros de adoctrinamiento para la juventud. (...) En los primeros años de su gobierno Perón continuó con las tendencias ideológicas en materia educativa que habían sido establecidas por sus predecesores inmediatos. Hacia 1950, sin embargo, el régimen peronista se hallaba embarcado en una dinámica de autoglorificación que requería el monopolio por parte del gobierno del espacio simbólico social. Perón gradualmente redefinió los elementos componentes del patrón ideológico establecido en 1943 a efectos de ajustarlo a los vagos dictados de la "doctrina". De esta manera, en el discurso oficial, la idea de lealtad a la nación fue transformada en lealtad al Estado, y gradualmente en lealtad al peronismo y a Perón como encarnación de la idea de EstadoNación. (PLOTKIN, 2007, p. 173-4)
\end{abstract}

Ahora bien, en virtud de comparar el proyecto educativo peronista con el de los gobiernos conservadores, el autor afirma que a pesar de las intenciones democratizadoras del discurso oficial, el sistema de educación técnica propugnado por Perón era de carácter reaccionario porque mantenía la división clasista, dado que la educación de la clase obrera no tenía conexiones con el sistema educativo regular. En este punto Somoza Rodríguez aclara que el concepto de "segmentación" se utiliza para definir el carácter de división clasista de un sistema educativo. Y advierte que ese concepto permite explicar el modo que se utiliza para 
frenar la movilidad social a través de la subdivisión en escuelas o en programas paralelos que difieren tanto en sus planes de estudio como en los orígenes sociales de sus estudiantes. Ahora bien, como explica este autor, el peronismo favoreció una "segmentación positiva", debido a que tendía a acelerar el ascenso social de los sectores obreros por medio de la enseñanza técnica, en desmedro de las modalidades tradicionales ( $y$ con mayor prestigio social) de enseñanza. Por lo tanto, durante el período peronista la enseñanza técnica promovió la movilidad social y ello obviamente apuntaba a fortalecer el proyecto político del peronismo. En definitiva, la calificación de la enseñanza técnica peronista como reaccionaria basándose en ese tipo de argumentación, carece de fundamentos sólidos. (SOMOZA RODRIGUEZ, 2006, p. 38)

$\mathrm{El}$ análisis que realiza Plotkin sobre el proceso de democratización del sistema educativo no resulta exhaustivo. Respecto del Primer Plan Quinquenal menciona el proyecto de la democratización en todos los niveles, la intención de ampliar el programa de educación técnica y de avanzar en la justicia social. Asimismo destaca el proyecto de ley universitaria que eliminaba su autonomía y prohibía las actividades políticas en la misma universidad. También refiere al proyecto de reorganización del Consejo Nacional de Educación para extender su jurisdicción a la enseñanza secundaria y técnica, el plan de gratuidad de todos los niveles de educación para aquellos que no pudieran pagar y la creación de la Universidad Obrera Nacional. Sin embargo, no incluye sino al final del libro -en un apéndice- los datos de la ampliación del sistema educativo y el aumento de establecimientos de enseñanza, de incremento de alumnos en todos los niveles y la reducción del número de analfabetos. Tampoco indaga en profundidad los cambios ocurridos en los colegios secundarios y en las universidades. En cambio, el autor profundiza en su investigación el proceso de inculcación doctrinaria.

Del Segundo Plan Quinquenal, Plotkin examina el discurso oficial a propósito de la campaña de adoctrinamiento. Incluye una selección de decretos y discursos en los cuales se definen los postulados, los objetivos y la necesidad de difundir la doctrina nacional. Aquí agudiza su análisis y reúne documentación para sostener este proceso de peronización que describe. Los homenajes a la memoria 
de Evita, la inculcación a través de los libros de texto, la proclamación de Perón como el primer adoctrinador de la nación, la equiparación, en virtud de la propaganda del plan, entre la escuela y la unidad básica. Asimismo, el autor se extiende en el proceso de centralización del sistema educativo y en las reformas de la ley universitaria, donde se contribuía a aumentar el poder y el control por parte del Estado.

Por otro lado, a través del análisis de los contenidos de los textos escolares, Plotkin aborda cuestiones relacionadas con el vínculo entre las clases sociales, el valor otorgado al trabajo y a la justicia social, el rol asignado al Estado, los conceptos de Patria y nacionalidad, las modificaciones en el panteón de héroes y próceres nacionales, entre otros. Si bien consideramos que aquí radica el punto más fuerte de la investigación de este autor, podemos observar que hubiera sido relevante revisar los textos de los niveles superiores a fin de tener una visión no sólo más amplia en términos cuantitativos sino también más profunda en el sentido de la complejidad que adopta el abordaje conceptual en los niveles superiores. Finalmente su conclusión, luego de subrayar la operación de exaltación del régimen peronista a través de los libros de texto, consiste en reconocer una tensión entre la campaña de peronización y la contribución a la modernización de la estructura del sistema educativo.

Somoza Rodríguez realiza varias críticas a la investigación de Plotkin. En primer lugar, sostiene que su principal debilidad se encuentra en la inscripción a un sistema conceptual e interpretativo que asume las formulaciones más tradicionales de las corrientes liberales y funcionalistas. A pesar de utilizar categorías de análisis actuales sus tesis centrales se aproximan al discurso político de los opositores liberales sostenido en las décadas del ' 40 y del '50. En este sentido, advierte que la distinción entre el sistema educativo peronista y los sistemas educativos precedentes basada en el carácter autoritario y adoctrinador de éste último se inscribe en la tradición histórica argentina a propósito de la anomalía que constituye el peronismo. Este tipo de caracterizaciones es consecuencia del modelo explicativo basado en la "manipulación" y la "agencia de adoctrinamiento" sustentado en la tendencia historiográfica de corte liberal y positivista que sostiene 
la "anomalía" del caso peronista en la tradición histórico-política del país y, aún más específicamente, en la tradición histórico-educativa.

Asimismo, esta naturaleza diferente se manifiesta en las expresiones mediante las cuales Plotkin interpreta los distintos procesos de socialización. Su interpretación se sostiene en una supuesta neutralidad ideológica y política del sistema educativo pre-peronista y omite que la transmisión de dogmas y el adoctrinamiento ideológico fueron procedimientos propios desde los orígenes del sistema educativo. Si bien destaca que el denominador común fue la educación patriótica, principalmente en la década de 1910 y de 1930, también reconoce la intención de transmitir un mensaje político más preciso. Ahora bien, sólo cita un ejemplo: en 1932 se obligó a los maestros que impartieran clases en las cuales se promocionara el empréstito patriótico cuyos bonos el gobierno estaba emitiendo.

Sin ahondar en la extensa literatura de los teóricos de la reproducción, es reconocido desde las ciencias sociales que la escuela ocupa un lugar preponderante entre los diversos procedimientos e instituciones que se encargan de la socialización política. Pero el modo en que se establece este procedimiento es histórico y está sujeto a variaciones. Es decir, el peronismo perseguía propósitos políticos al igual que las anteriores administraciones liberales y conservadoras. Sin embargo, de acuerdo con Plotkin, el sistema educativo oficial pasa de ser un poderoso instrumento para el "consenso liberal" y se transforma en una "herramienta para el adoctrinamiento político de la juventud".

\section{El discreto encanto de la retórica consensualista}

El procedimiento discursivo de neutralización y despolitización es característico del paradigma liberal, cuya retórica consensualista se sustenta en un enfoque puramente tecnicista de la política. El encanto de la idea de "consenso" reside en su aparente distanciamiento de posiciones ideológicas. En cambio, es interesante la observación que realiza Somoza Rodríguez acerca del matiz negativo que conlleva en la actualidad la idea de "adoctrinamiento" vinculada a la falta de libertad y autonomía de los adoctrinados o bien al "lavado de cerebro" y la despersonalización llevados a cabo por regímenes autoritarios. Sin embargo, 
"adoctrinamiento" remitía a la introducción de una persona en la doctrina, que podría ser liberal, comunista, religiosa, etc. Somoza Rodríguez nos advierte sobre las diferencias de significado social de las palabras que encontramos en la documentación histórica (SOMOZA RODRIGUEZ, 2006, p. 101-2). Y continúa su análisis del uso discursivo de este concepto precisamente en las conferencias de Perón sobre conducción política del año 1951. Allí se observa que de acuerdo con la discursividad peronista la doctrina es una creencia racional constituida por un corpus de saberes que conforman la identidad del sujeto, el cual llega por convicción personal y no como resultado de una imposición. En este sentido se interpela a través de la persuasión y se persigue la libre adhesión del individuo.

Finalmente el autor avanza y afirma que Perón no propuso nada muy diferente a lo que efectivamente existía en la Argentina, si bien la magnitud y extensión de la difusión de su doctrina no se había conocido en el país hasta entonces. Pero claramente se aplicaron procesos adoctrinadores en la época de Sarmiento, de Roca, en la educación patriótica de Ramos Mejía, o en la Década Infame. En este sentido, Carlos Escudé afirma que "Con Perón, uno de los cambios evolutivos yacía en el traslado del énfasis de lo patriótico a lo partidario (...) pero la intención era, como siempre, la de adoctrinar, principal función de la escuela desde 1908, y Perón pudo adoctrinar tanto y tan exitosamente porque los mecanismos ya estaban montados y porque la cultura ya aceptaba la legitimidad de esa función del aparato educativo" (ESCUDE, 1990, p. 157-8).

Coincidimos con Somoza Rodríguez en que la interpretación de Plotkin del sistema educativo como "agencia de adoctrinamiento" resulta limitada e insuficiente para abarcar el proyecto político-educativo del peronismo. A pesar de que la manipulación exista es necesario reconocer que las relaciones entre dirigentes y dirigidos son más complejas. Ese esquema de explicación reduce la multiplicidad de relaciones a una monocausalidad social. Incluso en su crítica agrega que la relación de liderazgo debe considerarse como un proceso colectivo relacionado con el funcionamiento del grupo, más que como la habilidad o cualidad poseída por un individuo. En este caso es necesaria una explicación del tipo de vínculos que se establecen entre líder y seguidores, de las motivaciones e 
intenciones de uno y otros, de los recursos y dispositivos que unos y otros introducen en el juego y, por otra parte, del marco social, económico y político en el que tales vínculos se originan y desarrollan. Ello implicaría una relación constitutiva entre ambos y no una relación de exterioridad entre el manipulador y la masa manipulada.

Esto refuerza la hipótesis de que no se trata de limitaciones temáticas y metodológicas sino que los principios interpretativos que utiliza Plotkin están próximos a la tradicional idea elitista de atribuir intencionalidad consciente a las conductas de personas, grupos o clases dirigentes, e ignorancia o inconsciencia a los comportamientos de las personas, grupos o clases subalternas.

Si revisamos algunas premisas de la tradición antiperonista, podemos apreciar cómo Plotkin las retoma en su investigación y lleva a cabo un análisis sesgado de contenido ideológico. Podemos mencionar, en sintonía con la tradición referida en el párrafo anterior, el presupuesto de la naturaleza totalitaria del movimiento político y sus procedimientos de manipulación demagógica sobre los sectores populares, considerados inmaduros cultural y políticamente a diferencia de la madurez y experiencia que inmunizaba a las clases medias. En este sentido, según Gino Germani, para las elites que dirigieron el proceso independentista en la Argentina, estaba en juego, además de la conformación del Estado nacional, la necesidad de dirigir los destinos de un pueblo menor de edad, irracional y maleable:

(...) la expresión de una voluntad política limitada a los estratos "culturales y responsables" de la sociedad (...) Para los estratos populares, por el contrario, no podía hablarse, de ningún modo, de una ideología democrática, sino de sentimientos democráticos, sentimientos que buscaban su expresión en formas también concretas e inmediatas (tal como ocurría con sus sentimientos de nacionalidad), y que se exteriorizó en definitiva con la adhesión a caudillos locales, de tipo autoritario, y que eran portadores de los mismos rasgos psicológicos y sociales que caracterizaban a sus partidarios. (GERMANI, 1971, p. 181).

Continuando con la idea de manipulación, encontramos otro supuesto que sostiene que las políticas distributivas, el gasto social y las mejoras de las 
condiciones laborales de los sectores populares, son operaciones demagógicas que llevaron al país a la exclusión y marginación de los organismos internacionales, obstaculizando la inversión de capitales e impidiendo el desarrollo y la modernización. Es necesario contextualizar este argumento a fin de reconocer las cadenas asociativas que en él se condensan.

En la segunda posguerra, la perspectiva de la modernización intentó dar respuesta a las diferencias en torno a las experiencias de desarrollo de algunos países occidentales y el resto del mundo. Como supuesto básico de dicho enfoque podemos señalar el uso de ciertas categorías y sistemas de valores deudores de la sociología del siglo XIX. En este sentido, uno de los anclajes analíticos es la concepción de la estructura social como un continuo que evoluciona desde una polaridad a otra: de una organización tradicional a un sistema moderno. Este análisis tipológico supone una determinada concepción de las propiedades y funcionamiento de las sociedades tradicionales y de las sociedades modernas, $y$, claramente, una valoración positiva de las segundas frente a las primeras. Por tanto, las respuestas que elaboran los teóricos de la modernización para explicar las diferentes experiencias de desarrollo, residen en subrayar las particularidades culturales, propias de las sociedades tradicionales, como posibles obstáculos para el camino de la modernización.

Si bien no se trata de una escuela unitaria de pensamiento podemos sintetizar los elementos centrales para caracterizarla en sus rasgos generales: se trata de un enfoque estructural-funcionalista que se sostiene en la imposición de categorías universales y en la creencia en un determinismo férreo, en un automatismo del crecimiento y en una unilinealidad en el desarrollo ascendente. Su análisis se centra en el contexto nacional y excluye el internacional. Asimismo, utiliza como concepto central para explicar el cambio y la transformación a la racionalidad.

En definitiva, según esta perspectiva, todas las sociedades debían converger en un modelo único de sistema político y económico. Y esto era posible en virtud de alcanzar ciertas condiciones necesarias a partir de las cuales el recorrido hacia el desarrollo estaba garantizado. De esta manera el supuesto que subyace es que a 
estadios económicos, sociales y políticos similares se desemboca en procesos semejantes. Así, el proceso de cambio se explicaba a partir de principios universales que guiaban un modelo único de desarrollo posible.

Es preciso aclarar que, según esta teoría, los rasgos de carácter moderno y racional postulados como modelo a seguir son: la ruptura de los lazos comunitarios tradicionales, la urbanización, la alfabetización, la industrialización, la influencia de los medios de comunicación de masas, el aumento de la renta per cápita, la movilización social, el crecimiento de las clases medias, la moderación política, entre otros. Todo ello contribuiría a un mayor desarrollo económico y a democracias más estables. Estas formulaciones teóricas se apoyaban en un determinado contexto intelectual y en cierta coyuntura económica. En primer lugar, la revolución conductista colocaría su énfasis sobre el comportamiento político más que sobre las instituciones. Así, si las condiciones estructurales y de coyuntura se presentaban favorables, el desarrollo dependería de la capacidad de tomar las decisiones de política económica adecuadas. De esta manera, el conflicto de intereses y la asimetría económica y política, se ocultaban bajo el velo de la racionalidad y la eficacia. ${ }^{4}$

En suma, si tomamos en cuenta los fundamentos que sostienen el ideal del consenso y la modernización y advertimos el sesgo ideológico al postular un pasado institucional modélico e idealizado y al aplicar de manera ahistórica y asocial la ideología liberal como único eje legítimo del desarrollo histórico de la humanidad, entonces se evidencia la operación que dicha construcción conceptual lleva a cabo para encubrir el hecho de que la transmisión de dogmas y el adoctrinamiento ideológico fueron atributos inherentes al sistema educativo argentino desde sus comienzos.

Asimismo, es ineludible el aporte de la pedagogía crítica que demuestra el carácter ideológico-político de las prácticas pedagógicas. Es necesario reconocer la

\footnotetext{
${ }^{4}$ Ver: CARDOSO, F. H.; FALETTO, E., Dependencia y desarrollo en América Latin., México: Siglo XXI, 1969; VALENZUELA, J. S.; VALENZUELA, A., "Modernization and Dependency. Alternative Perspectives. In the Study of Latin American Underdevelopment". In: Comparative Politics 10. $\mathrm{n}^{\circ} 4$, July 1978, p. 535-552; LIPSET, S.; SOLARI, A. (comp.). Elites in Latin America, Oxford: Oxford University Press, 1970.
} 
presencia de la cultura dominante en la elaboración del currículum oficial, la utilización del programa escolar para la legitimación de determinados saberes en desmedro de otros, para la producción de verdades y para ocultar, detrás del velo de la objetividad y la neutralidad, el conflicto en todas sus expresiones. ${ }^{5}$

De acuerdo con lo expresado anteriormente al tornar visible la relación intrínseca entre educación y política, lo central es abordar el examen de los principios filosóficos y políticos que subyacen a los proyectos de construcción de hegemonía.

\section{El sistema educativo como "máquina procesadora de demandas"}

Bernetti y Puiggrós se proponen discutir, por un lado, la hipótesis acerca de la educación peronista como culminación del proyecto positivista de Ramos Mejía y, por otro, la concepción de la política educativa como un producto continuo y uniforme de una "clase dirigente" supuestamente homogénea. En cambio, intentan analizar la política educativa como una serie de discursos producidos en el marco de las luchas por la hegemonía. En este aspecto, afirman que el peronismo operó una nueva articulación entre el concepto de nación y el de pueblo que produjo un reordenamiento del conjunto de los sujetos en el escenario de estas luchas. Asimismo sostienen que la década peronista constituye el punto de mayor despliegue del Estado-Nación moderno en la Argentina. Y, a pesar de la existencia de concepciones retrógradas en el campo de la educación justicialista del primer período, destacan las ideas fuerzas que guiaban su proyecto: los niños como los únicos privilegiados, el trabajo como valor organizador de la educación y la cultura del pueblo como cultura del Estado.

Su planteo, no intenta buscar un núcleo duro común en la cultura política argentina, ni asume que la trama discursiva de una época sea el efecto reflejo de un discurso dominante. Por el contrario, consideran las específicas articulaciones en cada momento histórico y para ello se proponen analizar las transformaciones

\footnotetext{
${ }^{5}$ Ver: APPLE, M. Ideología y currículo. Madrid: Akal, 1986; GIMENO SACRISTÁN, J. El currículo: una reflexión sobre la práctica. Madrid: Morata, 1991; GIROUX, H. A. Los profesores como intelectuales. Barcelona-Madrid: Paidós, 1990; MCLAREN, P. Pedagogía crítica y cultura depredador. Barcelona: Paidós, 1997.
} 


\section{Revista Sul-Americana de Filosofia e Educação - RESAFE}

discursivas, las equivalencias y diferencias entre los enunciados de distintas tendencias político-culturales e investigar la relación entre lo estructural y lo contingente.

Los autores observan que la retórica educacional de Perón no era totalmente ajena a las ideas presentes en el campo de la lucha político-culturalpedagógica de la época enfrentadas al conservadurismo liberal oligárquico. Coincidía con la búsqueda de unidad del sistema educativo y de la pedagogía, propia de las concepciones educacionales corrientes en la sociedad de los años '40. Rechazaba el biologicismo como base de tal unidad y por ello se diferenciaba de la pedagogía positivista. Reivindicaba como instrumento para producir la unidad, un racionalismo técnico-profesional-gremial sin abandonar la raigambre espiritualista. En suma, el discurso pedagógico-político de Perón advertía la decadencia del elemento positivista de la pedagogía normalizadora y pretendía construir y garantizar la reproducción de una nueva hegemonía sobre la base de un Estado fuerte, como unidad última de la organicidad social. No obstante, también señalan los autores que a comienzos de los '40, la posición proestatista de los maestros se combinaba con un profundo temor respecto a la forma en la cual el gobierno ejercía las funciones que los propios maestros le iban adjudicando o reconociendo.

La tesis central que defienden estos autores sostiene que es la sociedad civil la que elige al Estado como sujeto que deberá responder a una serie de demandas. Desde este punto de vista, argumentan que la sociedad civil desarrolló desde fines del siglo XIX diferentes modalidades para dar respuesta al conjunto de las necesidades educativas de las que el Estado conservador no se hacía cargo. Reconocen que durante el yrigoyenismo se ampliaron los servicios educativos estatales, aunque sin alcanzar modificaciones sustanciales del sistema escolar que se había consolidado entre 1884 y 1916. Y en la década de 1930 tanto aquel sistema como las sociedades populares de educación eran insuficientes para atender a su población potencial que había crecido considerablemente.

La demanda de capacitación para obreros, empleados, adultos y mujeres crecía no solamente como consecuencia del proceso económico-social de urbanización e industrialización y de la inmigración externa e interna, sino también 
por el creciente carácter complejo de los sujetos sociales. Sin embargo, la proliferación de ofertas educativas de organizaciones de la sociedad civil sociedades populares, academias, sindicatos, cursos en fábricas, de sociedades de beneficencia, organismos eclesiásticos y laicos, opciones cooperativas, etc.- fue insuficiente e inorgánica. De acuerdo con esta línea argumentativa:

Perón parece haber comprendido que se trataba de una interpelación dirigida al Estado para que se estableciera un nuevo orden que hiciera posible la respuesta organizada al conjunto de las demandas. La nueva organización debía articular lo diferente en una amalgama que estableciera pactos sociales y culturales entre los sectores que compartieran el proyecto nacional-popular. (BERNETTI y PUIGGROS, 2006, p. 93)

Por lo tanto, desde la posición del Estado interpelado, eran indispensables enunciados doctrinarios y filosóficos que sostuvieran argumentaciones sobre las reformas en la constitución del poder y legitimaran al propio Estado peronista de acuerdo con la intención fundadora de Perón. En este sentido, lo interesante de la investigación de Bernetti y Puiggrós radica en el extenso desarrollo de la base teórica del discurso pedagógico-político del período analizado. Para ello, por un lado, recorren determinados conceptos e ideas fundantes de la retórica peronista: la estrecha relación entre guerra, política y pedagogía; la idea de cultura entendida como preparación moral, arma de combate e instrumento para orientar la vida política; la concepción de la guerra total y la Nación en Armas de acuerdo con Karl von Clausewitz y el mariscal von der Goltz; la defensa nacional como problema integral; el modelo orgánico de Estado-sociedad; la unidad espiritual, el antipositivismo y el espiritualismo, la tercera posición, entre otros.

Por otro lado, profundizan en el pensamiento de algunos colaboradores importantes del gobierno peronista, analizando disertaciones y escritos de los más altos funcionarios oficiales del área educación a la luz de sus posiciones pedagógico-políticas. Recorren desde el grupo espiritualista de influencia alemana, en general englobado bajo el término culturalismo, de lectores de Dilthey, Litt, Spranger, Max Scheller, H. Noel y Karl Mannheim, y el antipositivismo italiano, en 
especial la versión vinculada al idealismo neohegeliano de Giovanni Gentile, que influyó en el conjunto de los pedagogos escolanovistas argentinos.

Asimismo al abordar la fundamentación filosófica de la pedagogía en este período, los autores indagan sobre las discusiones en torno al sujeto educacional y filosofía en el Congreso de 1949. Señalan que los sectores liberales laicos invitados no concurrieron y que la mayor parte de quienes estuvieron presentes o enviaron ponencias fueron figuras de la corriente aristotélico-tomista en sus diversas expresiones, y del existencialismo. En líneas generales, el Congreso reflejó la polémica que ya estaba presente en el área de educación de la dirigencia peronista entre una pedagogía de la esencia y una pedagogía de la existencia. Finalmente le dedican dos extensos capítulos al análisis, por un lado, de las reformas en el sistema educativo $\mathrm{y}$, por otro, de las fuerzas político-intelectuales que representaban a la Iglesia Católica.

Como corolario de este recorrido podemos advertir la sobredeterminación del accionar pedagógico en virtud de la importancia otorgada al mismo como instrumento de intervención política en las distintas esferas del gobierno peronista. En este sentido, la pedagogía se transforma en una forma de difusión de una filosofía en la cual confluye un modelo de organicidad y la intención de diseñar una tercera posición, sobre los principios de dignificación del trabajo y humanización del capital. De acuerdo con esta perspectiva, dignificar el trabajo y humanizar el capital están mediados por la formación integral del hombre. Esta es una de las articulaciones centrales como condición de posibilidad de la organicidad y del nuevo pacto social para conformar la Nueva Argentina. En las palabras de Perón, los conceptos de dignificación y humanización se vinculan con enunciados referidos a la serie de principios y sentimientos que forman el alma colectiva:

Sostiene que el alma colectiva se constituye por una serie de principios y sentimientos que diferencian a una masa como la que piensa en su conjunto de manera similar, que posee un objetivo en común y se aglutina detrás de un ideal y de sentimientos compartidos. No basta con pensar o sentir de la manera compartida para ser peronista: hay que hacer las dos cosas. Sin el sentimiento que constituye el espíritu colectivo no es posible la constitución del Movimiento, porque no son las fuerzas materiales 
ni las pasiones la fuerza motriz del hombre sino las fuerzas espirituales, aunque él las quiera resistir. Esas fuerzas espirituales deben tener una unidad última, sin la cual la organicidad social no es posible. (BERNETTI; PUIGGROS, 2006, p. 111).

Bernetti y Puiggrós subrayan no sólo la metaforización del discurso militar y religioso -inherentes a la identidad de Perón como militar argentino-, sino también la importancia de la Iglesia Católica y las Fuerzas Armadas en las acciones centralizadoras y la valoración positiva de la comunidad educativa respecto del rol de conducción del Estado Nacional como instancia capaz de ordenar el proceso de crecimiento del sistema. El reclamo se orientaba a que este último extendiera su capacidad de contención de la población que demandaba algún tipo de educación, de la organización del campo técnico-profesional docente y de la modernización del sistema escolar, en especial en su función de capacitador para el trabajo industrial y en servicios.

Somoza Rodríguez cuestiona la interpretación del accionar pedagógico bajo el gobierno peronista tanto como "máquina de adoctrinamiento" -desde el punto de vista de Plotkin- y como "instancia procesadora de demandas" -desde la perspectiva de Bernetti-Puiggrós. Acordamos con la primera crítica pero no coincidimos con la lectura que reduce la investigación que llevan a cabo Bernetti y Puiggrós de la compleja trama discursiva de la época en torno a las distintas tendencias educativas a una "instancia procesadora de demandas".

Su crítica simplifica la cuestión al argumentar que se trata de una lectura en clave justificativa y legitimadora de los procesos estudiados, en la cual se difumina el protagonismo de Perón y del Partido en las reformas educativas y se las reinterpreta como un conjunto de demandas provenientes de la sociedad civil, donde el Estado sólo se encarga de la ejecución bajo el mandato de ésta última. (SOMOZA RODRIGUEZ, 2006, p. 350)

Desde nuestro punto de vista, recae sobre los mismos presupuestos, pero en sentido inverso, que el autor cuestionaba al análisis de Plotkin. El mismo Somoza Rodríguez sostiene que las relaciones entre dirigentes y dirigidos son más complejas que el esquema maniqueo representado por un agente activo y manipulador y otro receptor y pasivo. Al afirmar que "se ubica a Perón y al peronismo como un actor 
secundario (procesador de demandas) frente a una sociedad civil (creadora de demandas) que desempeña el rol histórico y político protagónico" (SOMOZA RODRIGUEZ, 2006, p. 55) asume el presupuesto de exterioridad en la relación entre la masa manipuladora y el manipulado. Incluso insiste con la misma idea al afirmar que "Parece decirse que la fuerte presencia del aparato estatal en aquellos acontecimientos sólo tuvo una centralidad aparente y delgada, y que la sociedad civil era el verdadero poder detrás del trono." (SOMOZA RODRIGUEZ, 2006, p. 56)

En este sentido, omite el extenso y profundo análisis que realizan Bernetti y Puiggrós sobre el proyecto pedagógico-político de Perón para conformar un nuevo sujeto político que permita fundar una Nueva Argentina. La investigación de los autores se remonta a los fundamentos teóricos de Perón en su época de profesor a partir de sus Apuntes de Historia Militar de 1932. A lo largo del libro se analizan distintas intervenciones discursivas -ensayos, apuntes de clase, conferencias, discursos oficiales- en las cuales Perón explicita su proyecto de sociedad política.

Este autor ubica el análisis de Bernetti y Puiggrós en el extremo opuesto al esquema de interpretación de Plotkin y de Escudé, pero para ello reproduce el esquema monocausal, lineal y no dialéctico de agente y paciente. De este modo elude la verdadera polarización entre las dos interpretaciones analizadas que se manifiesta con claridad en el proyecto pedagógico-político que cada uno defiende. Por consiguiente consideramos una simplificación reducir la investigación de Bernetti y Puiggrós al esquema unidireccional de emisor-receptor.

Asimismo es curioso que el propio Somoza Rodríguez explicite la particular concepción sobre el sujeto pedagógico que maneja Puiggrós que precisamente conlleva a la negación del esquema maniqueo que obedece a una distribución estática y fija del carácter pasivo o activo al interior de una relación pedagógica.

La educación, como práctica productora de sujetos a partir de otros sujetos, es una mediación. Se realiza construyendo un sujeto mediador, que hemos llamado sujeto pedagógico. Con él nos referimos a la relación entre educador y educando, al producto de la vinculación entre los complejos sujetos sociales que ingresan a las situaciones educativas (por ejemplo, una niña, negra, garota, bahiense) y los educadores, también sujetos complejos (el 
educador popular, evangelista, hombre, riograndino, blanco) (...) Toda pedagogía define su sujeto. Cada una determina los elementos y el orden de las series que la construyen como conjunto significante, cuya función es mediar entre los sujetos políticos y sociales y el habitus que se pretende inculcar (...) Esta relación entre educador y educando, siempre mediada por el currículum (consciente e inconsciente, manifiesto u oculto, más planeado o más espontáneo, en germen, fragmentado o desarrollado) será denominada "sujeto pedagógico" (...) En los sistemas educativos latinoamericanos y en particular en el argentino, primó la "instrucción pública" sobre otras formas de sujeto pedagógico, desde su fundación. (PUIGGROS, 1990, p. 302)

En efecto, el sujeto pedagógico no refiere al individuo interpelado por la pedagogía, puesto que no remite a un agente, sino a un conjunto de procedimientos, intervenciones o acciones. Por lo tanto, si el sujeto pedagógico es la mediación entre los educadores y los educandos, entonces hay una clara concepción dialéctica en virtud de la cual se desprende una implicación recíproca que no obedece a una linealidad causal ascendente o descendente como pretende interpretar Somoza Rodríguez.

En definitiva, no advierte que la dialéctica entre teoría y práctica está presente en el proyecto pedagógico político y en la relación entre la multiplicidad de las demandas provenientes de la sociedad civil y la unidad del proyecto educativo.

Si sumamos a esta concepción del sujeto pedagógico la explícita intención de examinar las políticas educativas al interior de la trama discursiva de la época, entendiendo que no se trata del efecto reflejo de un discurso dominante, sino de una compleja interacción, entonces podemos observar el forzamiento de la interpretación de Somoza Rodríguez. Precisamente, la parte más débil de su investigación radica en su intención de postularse como una interpretación superadora de la polarización entre la tendencia liberal-positivista y la tendencia nacional-populista. Esta posición conciliadora se manifiesta en el reconocimiento del proceso de democratización del sistema educativo, pero destacando el carácter autoritario y los objetivos de manipulación de la socialización política del gobierno peronista. En el capítulo dedicado al liderazgo pedagógico de Perón afirma: 
Formando parte fundamental de su proyecto político, construyó una auto-imagen en la que, además de los rasgos propios de un líder político, confluían en ella la incuestionabilidad de un Padre de la Patria (grandeza de miras, sacrificio por una causa superior), los atributos de un educador (persuasión, explicación), y los de un sacerdote (predicación, convicción). A semejanza del panteón católico, Perón era Uno y Trino: Conductor, Maestro y Predicador. (...) nuevos tipos de relaciones sociales y políticas fueron promovidas por el populismo nacionalista $e$ instrumentalizadas para configurar un nuevo tipo de ciudadano y un nuevo tipo de consenso y hegemonía. Un resultado parcial de ello fue la proyección de una imagen paradigmática de líder político que perduró durante décadas en el imaginario social argentino. (SOMOZA RODRIGUEZ, 2006, p. 106).

La tesis central de este autor afirma que con el objetivo de consolidar un nuevo modelo político, social y cultural, el peronismo combinaba democratización económica y social junto con recursos coercitivos de control social para limitar la autonomía de los sujetos y encuadrarlos en su propio proyecto político. Ahora bien, si no adscribimos a la idea elitista de atribuir intencionalidad consciente a las clases dirigentes, e ignorancia o inconsciencia a clases subalternas, entonces la tesis anterior no entra en contradicción con la de Bernetti y Puiggrós.

Por lo tanto, una de las premisas fundamentales de cualquier proyecto democrático es aceptar la presencia de núcleos de conflicto que definen posiciones antagónicas, en definitiva, es reconocer la naturaleza conflictual de la política. Se trata de construir hegemonías que están atravesadas por luchas de intereses, posiciones y valores, porque lo que está en juego es la configuración misma de las relaciones de poder en torno a las cuales se estructura una determinada sociedad. Si nos inscribimos en el marco de un proyecto de lucha por la hegemonía lo que aquí habría que discutir es cuál es la viabilidad de la horizontalidad en el sistema educativo. ¿Cómo se manifiestan la igualdad y la libertad en la gestión descentralizada? ¿Es posible pensar desde el Estado al aparato ideológico escolar como ajeno a la lucha por la construcción de hegemonía o al margen de la reproducción de la ideología dominante? ¿La horizontalidad y la simetría son opciones viables para la construcción de una propuesta política democráticopopular? 
El desafío consiste en despojarse de los elevadísimos umbrales morales y teóricos que no encuentran nunca o casi nunca su realidad, para pensar la educación política sin caer en las aporías del ideal anarquista, la hipocresía liberal y la asimetría populista.

\section{El más explícito de los currículos implícitos}

Una coincidencia notoria entre los autores analizados es la de reconocer el valor otorgado por Perón al aparato escolar como un espacio de formación política y a la pedagogía como herramienta privilegiada en este quehacer. Incluso concuerdan en el carácter rupturista del peronismo respecto del modelo de construcción ciudadana fundacional. Sin embargo, desde una perspectiva, se hace hincapié en el autoritarismo y la manipulación a través de la propaganda política y, desde otra, se destaca la subversión de los valores liberales clásicos y la ampliación de los derechos sociales, civiles y políticos, anteriormente negados o menoscabados para amplias masas de argentinos.

Es preciso reconocer que, desde sus mismos orígenes, la escuela ha ocupado un lugar central en la formación de conciencia política. Si nos remontamos a la elite dirigente que inauguró el sistema educativo público podemos advertir una preocupación manifiesta por la educación, debido a que la escuela era percibida como un instrumento privilegiado para unificar las diversidades culturales y asimilar las masas de inmigrantes a fin de moldear la identidad nacional. Esta generación que abrevaba en ideas iluministas sobre la autonomía de la razón y la soberanía popular consideraba que el pueblo bárbaro y no instruido atentaba contra el orden institucional. Por consiguiente, debía ser tutelado y limitada su participación política al mínimo gesto sufragante a fin de delegar su soberanía a la elite iluminada. De este modo, la formación del ciudadano adquirió una impronta de neutralidad y moralidad, con la intención homogeneizadora para evitar el conflicto y las pluralidades políticas.

Ahora bien, ¿es posible una educación política neutral? ¿Qué formación política se busca brindar a través de la neutralidad? En el contexto de un país con extensas luchas fraticidas la neutralidad adquiere sentido como garantía para la 
convivencia en el ámbito escolar de los hijos de bandos irreconciliables. Incluso puede percibirse como vía de expresión del ideario de los vencedores, para que los vencidos sepan a quién elegir para deliberar en su nombre. (SIEDE, 2007, p. 167).

El relato de la neutralidad y la moralidad se centra en las carencias de los dominados y supone formas de dominación que los silencian. Así, se instituye y se reproduce la incapacidad de éstos últimos de decidir por sí mismos y contribuye a mantener una condición de sometimiento implícitamente aceptada por todos.

El pensamiento pedagógico y político de la generación del '37 revela el peligro que las masas bárbaras constituyen para su proyecto de fundación republicana. Se expresa claramente en la fórmula de Alberdi:

(...) que procura conciliar los valores igualitarios de una república abierta a todos con los valores jerárquicos de una república restrictiva, circunscripta a unos pocos. La piedra de toque de esta fórmula tiene sencillo diseño: funda una capacidad de decisión dominante para el poder político central; otorga el ejercicio del gobierno a una minoría privilegiada; limita la participación política del resto de la población; y asegura a todos los habitantes, sin distinción de nacionalidad, el máximo de garantías en orden a su actividad civil. (BOTANA, 1986, p. 46)

De este modo, podemos apreciar cómo el relato fundacional del régimen republicano de apología del equilibrio y la institucionalidad, en la práctica, limitaba el ejercicio de los derechos políticos, utilizaba un sistema electoral violento y fraudulento y funcionaba como un régimen monárquico. Se combinaba, por un lado, la organización del Estado con un orden conservador estructurado sobre valores políticos liberales y aristocráticos y, por el otro, mediante la acción represiva pero con la bandera de la civilización, se lograba la obediencia y se sometía a las mayorías relegadas social, económica y políticamente. A través de la institución escolar se promovía la adhesión a determinados valores y se formaba a las elites locales para ejercer la conducción política. De esto se deriva que “(...) el sistema educativo argentino tuvo en sus orígenes como finalidades principales disciplinar $e$ integrar consensualmente a los sectores populares bajo el colectivo ciudadanos y 
funcionar como instancias de legitimación y formación política de las elites gobernantes." (PINEAU, 1997, p. 18).

Desde esta perspectiva queda al desnudo la supuesta neutralidad de la educación. El Estado liberal erige como el guardián de las libertades civiles pero en la práctica asegura la protección de los intereses dominantes y la estabilidad del orden político fundado sobre el poder de las élites. De acuerdo con Botana un selecto grupo de notables de las elites provinciales conformaba una oligarquía que fajo la hegemonía del Presidente de la Nación controlaba la sucesión política y el modelo de construcción ciudadana se elaboraba sobre las bases del nacionalismo, el patriotismo, el acatamiento del orden social y político establecido y la participación política restringida al ejercicio del sufragio.

En suma, la valoración de lo pedagógico en función de lo político y la necesidad de profundizar determinados aspectos escolares en detrimento de otros para garantizar un proyecto estatal estuvo presente en los distintos regímenes gubernamentales, la diferencia reside en que el peronismo tornó más visible la naturaleza de la relación entre educación y política y, en particular, los dispositivos de control y vigilancia. Así, el currículum implícito se hacía explícito.

\section{Consideraciones finales}

En definitiva, la subordinación de lo pedagógico a los objetivos políticos del Estado está presente, de un modo más o menos transparente, en los distintos regímenes políticos. Sin embargo, como afirmamos anteriormente, en el caso particular del gobierno peronista el currículum oculto se hace peligrosamente explícito.

Desde su origen, la institución escolar se conformó como un lugar de formación de la conciencia política y a través de ésta de legitimación de las políticas de Estado. Desde las políticas públicas se elaboran propuestas educativas para ser impuestas a fin de adoctrinar conforme a determinados valores en orden a modelar individuos afines al régimen imperante, o bien, en términos más amables, para construir consenso. Por consiguiente, consideramos que en el debate actual es preciso discutir cuál es el proyecto de política pública que se pretende legitimar y 
reproducir a través del uso del aparato escolar. Incluso tomando en consideración que las resoluciones oficiales y los diseños curriculares no tienen directa traducción en el aula ni en la participación política de los ciudadanos.

Asimismo, es de vital importancia revisar los supuestos que sostienen a la categoría de ciudadanía como constitutiva de la subjetividad política y la consideración acerca de que el incremento y mejora de la formación ciudadana en la escuela es condición necesaria y suficiente para el desarrollo futuro de la sociedad.

En la actualidad los procesos de fragmentación de la ciudadanía y la desmaterialización de los derechos laborales y sociales, conducen a la construcción de ciudadanías no tanto en cuestión de derechos, sino de redes sociales que se forman en la periferia. En este caso, es necesario indagar sobre los nuevos modelos de ciudadanía restringida, producto de la desregulación e individualización del modelo neoliberal. A su vez es relevante reflexionar sobre las nuevas subjetividades políticas que este modelo quiere invisibilizar.

La apología que lleva a cabo el discurso neoliberal del consenso, del diálogo, de la conciliación y de la síntesis superadora encubre la cuestión central que es qué interés político emprende la tarea de la síntesis o la conciliación. Claramente la neutralización y despolitización tienen un sentido político, como por ejemplo cuando se invoca a la Paz o a la Humanidad como instrumento ideológico para expansiones del poder económico. Así, a través de un sistema de conceptos despolitizados, que oscilan entre la espiritualidad ética y la objetividad económica, se busca legitimar las aspiraciones políticas propias y descalificar o desmoralizar al oponente. De acuerdo con Chantal Mouffe:

Lo que está en juego en la lucha agonista es la configuración misma de las relaciones de poder en torno a las cuales se estructura una determinada sociedad: es una lucha entre proyectos hegemónicos opuestos que nunca pueden reconciliarse de un modo racional. La dimensión antagónica está siempre presente, es una confrontación real, pero que se desarrolla bajo condiciones reguladas por un conjunto de procedimientos democráticos aceptados por los adversarios. (MOUFFE, 2009, p. 28). 
En cambio, para la perspectiva liberal-consensualista ${ }^{6}$ es necesario desterrar el antagonismo de la política, dado que la democracia es entendida en términos de consenso y reconciliación. Esto es posible en virtud de un acuerdo racional en el marco de instituciones que regulan a través de procedimientos imparciales la reconciliación de intereses y valores en conflicto. Desde este enfoque racional $e$ individualista la hostilidad en política se vincula con las formas del pasado y puede ser superada a través del intercambio y el establecimiento de una comunicación transparente entre los participantes de una comunidad racional. Por lo tanto, no hay adversarios sino competidores y el campo de la política constituye un escenario neutral en el cual cada individuo compite para ocupar posiciones de poder. Asimismo, desde esta perspectiva, la universalización de la democracia liberal anticipa un mundo más allá de la izquierda y la derecha, más allá del antagonismo y más allá de la hegemonía vislumbrando un futuro cosmopolita con paz y prosperidad.

En el proceso de adueñarnos de un recuerdo tal y como relumbra en el instante de un peligro advertimos que si bien es cierto que las condiciones globales han cambiado, podemos apreciar que ciertas condiciones se mantienen vigentes y los problemas se reiteran: los países centrales -desarrollados- buscan neutralizar la capacidad competitiva de los países periféricos -subdesarrollados-; la desorganización y falta de cohesión nacional; las elites locales defienden sus propios intereses a corto plazo; la falta de acuerdo nacional; la ausencia de una burguesía nacional unida e influyente y comprometida con un proyecto a largo plazo en pos de la autonomía económica; la concentración del ingreso; los rentistas apoyados en el sistema financiero; los desequilibrios regionales y la inestable movilización y apoyo popular. Además, el Estado resignifica sus funciones intervencionistas, de control y de regulación económica y tiende a favorecer los capitales de origen nacional, a expandir el mercado interno y la capacidad de consumo de la sociedad. Asimismo, potencia sus actividades empresariales al estatizar empresas de servicios públicos. Se trata de un Estado que rebasa los

\footnotetext{
${ }^{6}$ En referencia al paradigma liberal agregativo (J. A. Schumpeter), el deliberativo (J. Rawls y J. Habermas) y la modernización reflexiva (A. Giddens y U. Beck).
} 
límites tradicionales del liberalismo y, por ende, sufrirá las críticas de los sectores de la elite perjudicados por la pérdida de privilegios y del acceso al poder político. Incluso, el acceso de los sectores populares al consumo de determinados bienes culturales restringe la capacidad de penetración de la cultura en las clases medias, beneficiadas económicamente por sus políticas, pero que se sienten amenazadas por la pérdida de sus privilegios y de sus espacios sociales tradicionales sostenidos en los valores liberales.

La articulación histórica del pasado puede conducirnos a la desazón del eterno retorno. Sin embargo, consideramos que la naturaleza prescriptiva de la política invita a proponer algo acerca de qué hacer, porque a menudo se termina negando mucho más de lo que se denuncia. La política no sólo es crítica y negación, también es afirmación. Por lo tanto, en nuestra reflexión contemporánea relativa a la cuestión educativa es preciso reconocer la institucionalización de la lucha de las visiones del mundo y la necesidad de optar y decidir entre alternativas en conflicto. Asimismo, si no abogamos por soluciones radicales como la desescolarización de Iván Illich y aceptamos la mediación de las instituciones, entonces para no reproducir procedimientos ritualizados sin sentido es de vital importancia intervenir generando conocimiento que devenga en prácticas y dispositivos reales de acción política y educativa.

\section{REFERENCIAS BIBLIOGRÁFICAS}

BERNETTI, J. L.; PUIGGRÓS A. Peronismo: Cultura política y educación (19451955). Buenos Aires: Galerna, 2006.

BOTANA, N. El Orden Conservador. La politica argentina entre 1880 y 1916. Buenos Aires: Hyspamérica, 1986.

ESCUDÉ, C. El fracaso del proyecto argentino. Educación e ideología, Buenos Aires: Tesis/Instituto Di Tella, 1990

GERMANI, G. Política y sociedad en una época de transición. De la sociedad tradicional a la sociedad de masas. Buenos Aires: Paidós, 1971.

MOUFFE, Ch. En torno a lo político. Buenos Aires: F. C. E., 2009.

PINEAU, P. La escolarización de la Provincia de Buenos Aires (1875-1930). Una versión posible. Buenos Aires: Oficina de publicaciones del CBC-UBA, 1997.

PLOTKIN, M. B. Mañana es San Perón Propaganda, rituales políticos y educación en el régimen peronista (1946-1955). Buenos Aires: Eduntref, 2007. 
PUIGGRÓS, A. Sujetos, disciplina y currículum en los orígenes del sistema educativo argentino. Buenos Aires: Galerna, 1990.

SIEDE, I. A. "La función política de la escuela en busca de un espacio en el currículum" In: SCHUJMAN, G.; SIEDE, I. Ciudadanía para armar Aportes para la formación ética y política. Buenos Aires: AIQUE, 2007.

SOMOZA RODRíGUEZ, M. Educación y Política en Argentina (1946-1955). Buenos Aires: Miño y Dávila, 2006.

TEDESCO, J. C. Educación y sociedad en Argentina. 1880-1945. Buenos Aires: Solar, 1986.

TORRE, J. C.; PASTORIZA, E. "La democratización del bienestar". In: TORRE, J. C. (Dir.). Los años peronistas (1943-1955). Buenos Aires: Sudamericana, 2002.

Recebido em 28/10/2010.

Aprovado em 17/12/2010. 